Tony Atkinson's new book, Measuring Poverty Around the World. Some further reflections

Andrea Brandolini John Micklewright

Quantitative Social Science Working Paper No. 20-15

October 2020 


\section{Disclaimer}

Any opinions expressed here are those of the author(s) and not those of the UCL Social Research Institute. Research published in this series may include views on policy, but the institute itself takes no institutional policy positions.

QSS Workings Papers often represent preliminary work and are circulated to encourage discussion. Citation of such a paper should account for its provisional character. A revised version may be available directly from the author.

Quantitative Social Science UCL Social Research Institute University College London 55-59 Gordon Square London WC1H ONU 


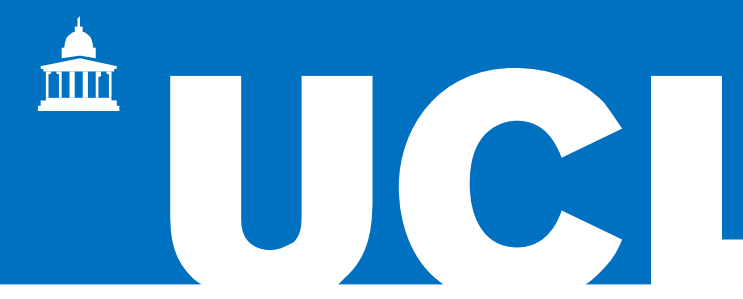

\title{
Tony Atkinson's new book, Measuring Poverty Around the World. Some further reflections
}

\author{
Andrea Brandolini ${ }^{1}$ \\ John Micklewright ${ }^{2}$
}

\begin{abstract}
A new book on measuring global poverty by the late Tony Atkinson was published in 2019 by Princeton University Press. We describe how we edited the incomplete manuscript that Atkinson left at his death, the additions we made (which include afterwords by François Bourguignon and Nick Stern), and the content and structure of the book. We then discuss what we believe Atkinson was trying to achieve, emphasising both the important insights of the book and where the gaps remain. We also review parallel developments in the World Bank's measurement of global poverty that were stimulated by the report of the Commission on Global Poverty, written by Atkinson, from which this book was developed. The new book is more than four hundred published pages. It remains unfinished yet it is a masterly guide to the nuances of poverty measurement and an invaluable source for future research.
\end{abstract}

Keywords: global poverty, income, consumption, multidimensional poverty, cosmopolitanism.

JEL codes: $\mathrm{C} 80, \mathrm{I} 32$

Acknowledgements: This paper is based on and further develops our foreword to Atkinson (2019). We benefitted from discussion at presentations of Tony's book. In particular, we are grateful to Elena Granaglia, Tonia Mastrobuoni and Giovanni Vecchi (Festival dell'economia 2019, Trento), Francesca Bastagli, Torsten Bell, Rachel Glennerster, Nick Stern (Resolution Foundation, London), Chico Ferreira, Stephen Jenkins, Ingrid Robeyns (Human Development and Capability Association conference, London), Sabina Alkire and Brian Nolan (Oxford Martin School, Oxford), and Tricia Keilthy and Brian Nolan (The Statistical and Social Inquiry Society of Ireland, Dublin). We have also benefitted from reading early reviews of the book including Faktorovich (2019), lacono (2019), Ravallion (2019), and Sivaraman (2019). The views expressed here are solely ours and they do not necessarily reflect those of the Bank of Italy or the Eurosystem.

\footnotetext{
${ }^{1}$ Banca d'Italia

${ }^{2}$ University College London and IZA
} 


\section{Introduction}

Tony Atkinson's death on 1 January 2017 deprived social science of one of its finest scholars. His magnum opus Inequality: What Can Be Done? (Atkinson, 2015), translated into more than a dozen other languages, is often talked of as his last book. But the good news is that a new Atkinson book is now published. Measuring Poverty Around the World, from Princeton University Press (Atkinson, 2019; henceforth, $M P A W$ ), appears fifty years after Tony's first book, also on the subject of poverty, Poverty in Britain and the Reform of Social Security (Atkinson, 1969). That first book was restricted in coverage to just his home country. In a volume published twenty years later, his view was broadened to embrace the whole of Europe (Atkinson, 1998). With this book, Tony's perspective turns truly global in its compass.

In this paper we return to Tony's book, which we edited for publication, describing in more detail what we believe Tony was trying to achieve and where the gaps in the book remain. In doing so we mention parallel developments since Tony's death in the World Bank's measurement of global poverty, stimulated by his Commission on Global Poverty (CGP) report (World Bank, 2017), and how some of these differ from the direction Tony was taking in his book. In Section 2 we explain the thrust of the book and our editorial work. We discuss three aspects of the book that, in our view, characterise Tony's original look at the problem at hand in Section 3 and his 'principled' approach in Section 4. Then, we deal with the importance of statistical assumptions and data in Section 5. In Section 6 we turn to the second part of the book dealing with the interpretation of empirical evidence and the analysis of several substantive issues. In Section 7 we conclude.

\section{The thrust of the book and our editorial work}

Tony's book is not an exercise in statistics, although statistics are a central theme of the book. Tony takes seriously the first of the seventeen UN Sustainable Development Goals (SDGs): the ending of poverty, 'everywhere'. His purpose is then to convince readers that measurement is fundamental in tackling this key challenge to humanity. Better measurement is essential for raising awareness of poverty, for motivating action to address it, for designing good policy, for gauging progress towards goals, and for holding political leaders accountable for meeting targets. By examining how poverty is - and should be - measured, Tony provides an inspiring guide to understand poverty and policies to fight it. 
The book is about measurement of poverty 'around the world' in two senses. First, it leads readers through the nuances of measurement used in individual countries. 'Around' in this sense means 'anywhere'. How can one go about measuring poverty in any particular country, rich or poor? The book's chapters illustrate Tony's arguments with numerous examples, in part drawing on an appendix that was planned to include national reports on poverty measurement for sixty different countries at all levels of development. Second, the book shows how one can arrive at a global total for poverty. Here, 'around' is a gathering together of all countries. How many poor people are there in the world? What are the steps needed to arrive at such a total and, critically, what are the assumptions that lie behind the calculations? In addition to providing a guide to measurement in these two senses, Tony had also planned to analyse a large amount of data on poverty trends and to discuss a range of substantive issues concerning poverty - for example poverty and climate change, poverty and growth, poverty and the colonial inheritance from European empires. The project was ambitious and the book's plain, unassuming title is restrictive as Tony's plan was to cover much more than 'just' measurement.

The book grew out of Tony's work chairing the CGP for the World Bank, the report of which he wrote single-handed and delivered in the summer of 2016 (World Bank, 2017). The report finished, he decided to write a book for a broader audience about the nature and extent of poverty across the world and in particular, but not only as we have noted, how to measure it. The book re-uses some of the text in the CGP report, but it goes much further. The report was written to advise the World Bank on two specific issues about its future measurement of poverty: how to update its methods based on households' consumption or income given that prices change over time and new rounds of international price comparisons become available, and whether and how to incorporate other (non-monetary) dimensions of poverty and deprivation into its measurement. The report contains little analysis of data. In contrast, Tony's book starts from first principles about the meaning of poverty, translates these principles into concrete measures, and then analyses the data to which the measures can be applied. It is much broader than the CGP report both in approach and in content, addressing a range of substantive issues alongside the data analysis, with a central emphasis on the integration of countries' own national measurements and the measures adopted by international organisations.

As the brief outline above already hints, sadly Tony was unable to carry through all his plans. But before his death he asked us to take his manuscript forward to publication. He left an incomplete first draft and no guidance on how he wished us to proceed. Neither of us 
had discussed the project with him. However, he also left a detailed list of all chapter sections and sub-sections together with a ten page summary of the book, written we are sure as a proposal for publishers (although never sent - he had secured no contract for the book). Tony's family gave us access to his working files, both on his computer and in paper form. In addition, one of us had been a member of the CGP and hence was familiar with Tony's starting point.

Of course, we could rely on many years of friendship, open discussion on multiple and diverse issues, and joint work on papers and books. But we quickly decided that completion of the book was impossible. There was too much left to do, especially in the book's second half. We might have imposed our own ideas and become co-authors (an option the Atkinson family suggested we consider) but we were clear from the outset that the book should remain Tony's alone. We therefore decided to bring the book to a state where it could be published while remaining incomplete.

We added a significant amount of material in the first half of the book with the aim of more or less finishing Tony's discussion of conceptual and practical issues in measuring poverty. Most additions are based on Tony's previous writings or on arguments we had long discussed with him. Others are straightforward updates for developments that Tony would have definitely included, such as those relating to the EU indicators of material deprivation or the Global Multidimensional Poverty Index. We added smaller amounts of text elsewhere and much of what Tony planned to cover in several chapters in the second half of the book is still missing. We also edited the sixty 'national reports' at the end of the book, adding and updating text and data, and writing reports for a few countries and drawing graphs for others, although nineteen of the reports remain largely skeletons without the flesh that Tony would have supplied. After some thinking, we decided that our edits and additions to the main text and to the national reports should not be visible to the reader: hopefully, the gain in readability outweighs the loss in philological precision (Faktorovich, 2019). On occasion, however, we added footnotes in which we comment explicitly as editors, for example on the direction that we think Tony may have planned to take in an unfinished section of his manuscript.

There are only two major exceptions in our resistance to filling the gaps beyond the interventions just described. In one of the chapters in the second half of the book, Tony had planned to discuss the relation between growth, inequality and poverty reduction and the relation between poverty reduction and action on climate change. Tony made clear that he saw both these issues as fundamental in the fight against poverty but he had no time to deal 
with them. We felt they should indeed be covered in his book. To fill the gaps, we asked François Bourguignon and Nick Stern, long standing co-authors and friends of Tony, leading scholars in these two areas, and both former Chief Economists of the World Bank, to deal with these subjects, which they did in two extensive afterwords.

The result is a book of over four hundred pages, with about two hundred and fifty pages of main text, including the afterwords, a hundred and twenty pages of national reports, and an extensive bibliography and index. There are thirty graphs, tables and boxes in the main text and a graph (two in the case of China) in each of the sixty national reports. The book is a substantial one despite being unfinished. Most likely, at the first round of revisions of his completed manuscript Tony would have not only polished the text but also cut it significantly.

\section{Tony's original look at global poverty measurement}

In Chapter 1 Tony sets the scene for the rest of the book and develops his ideas on the measurement of global poverty. In our view, the originality of Tony's approach emerges in the analysis of three important questions, which are likely to pave the way to new research.

First, Tony believes that the measurement of global poverty must be truly global. Typically, the World Bank's estimates excluded high income countries, as they were assumed to have no-one beneath the International Poverty Line of PPP\$1.90 a day per person, defined by the Bank as 'extreme' poverty. (PPP means here Purchasing Power Parities and refers to the fact that $\$ 1$ has the same purchasing power in any country thanks to the use of proper conversion rates from national currencies to the US\$.) Following his advice in the CGP report (World Bank, 2017, p. 47), the World Bank now includes these countries in its global poverty count and provides estimates for them in its public use databases. Unsurprisingly, the proportion of people living in extreme poverty in high income countries is tiny, 0.7 per cent against 9.9 per cent worldwide in 2015 , and is such not to affect the global count given population sizes. Although it confirms the geographical distribution of extreme poverty, this number helps draw attention to those 8 million and more individuals in the rich world who have resources insufficient even by the minimum standard applied by the World Bank in the poorest countries.

Conceptually, this is a revolutionary change that at last closes the gulf between rich countries and the rest of the world. At the same time, it highlights issues that may have been given insufficient consideration in measuring global poverty. On the one hand, the estimated number of people in extreme poverty in high income countries does not include those who do 
not live in registered households, and hence generally escape poverty counts, such as the homeless and those living in institutions, the illegal immigrants and the refugees. This in an important topic, one which will only gain in importance when the migrations that are expected to be caused by climate change will eventually materialise. Tony extensively deals with 'the missing', in rich and poor countries, in a specific section in Chapter 4 which he aptly concludes with the remark:

'As the total living below the International Poverty Line falls over time, the missing population will become proportionately more significant. Moreover, a number of the groups - such as refugees, the homeless and those living in war zones - have a particular claim on our compassion.' (MPAW, p. 131)

On the other hand, including high income countries raises the question of whether the International Poverty Line makes sense in advanced economies. Critiques of the World Bank's approach have long stressed that the International Poverty Line is too low to cover the purchasing of basic necessities in many countries, including the United States, the base country (e.g. Reddy and Pogge, 2010, Reddy and Lahoti, 2016). This criticism is partly accounted for by the World Bank's recent use of two lines set at higher levels (PPP\$3.20 and PPP \$5.50) as well as by the adoption of the 'societal' poverty line discussed below.

Second, Tony critically discusses an implicit, and overlooked, assumption in global poverty measurement. Estimates of global poverty, such as those made by the World Bank using the International Poverty Line, invariably weight each poor person around the world equally. Tony describes this as a 'cosmopolitan' approach to estimating global poverty and one that is entirely suitable for an international organisation such as the World Bank. However, he offers alternatives, which include the extreme position of an 'isolationist' approach in which poverty outside one's own country is ignored, and, more importantly, a 'limited sympathy' approach in which full weight is given to the poor within national borders and a weight less than 1 but greater than 0 to the poor in other countries. The latter is a possibility which has received virtually no attention in the literature on global poverty. It raises ethical as well as measurement questions. In particular, it would imply that the global poverty count is nationally specific and varies with the country where the calculation is made: 'the magnitude of world poverty as seen from India will be different from that seen from the US; the two world poverty counts may even be moving in opposite directions' (MPAW, pp. 13-4). 
The attention for the 'limited sympathy' approach is motivated by the fact that opinions differ: 'we have to recognise that sympathy may, in today's world, be less than complete, and that this needs to be reflected in the measures employed' (MPAW, p. 14). This recognition is echoed in the current debate on the impact of globalisation on inequalities between and within countries: 'Whether one thinks the last quarter century has been good or bad for equity depends critically on whether one takes a national or global perspective' (Rodrik, 2017, p. 1). We have no doubt that Tony would have stood on the 'cosmopolitan' side but, realism apart, his emphasis on 'limited sympathy' is a natural consequence of his conviction that measurement must allow for alternative ethical views. Although Tony examines this issue in the context of a discussion of instrumental versus intrinsic reasons for concern over poverty (he firmly favours the latter), his ideas here should be seen in the light of the intuition of his landmark paper on the measurement of inequality in the Journal of Economic Theory (JET) in 1970. Counting across countries requires an ethical judgement on how to weight each contribution to the count, and such judgement needs to be made explicit.

Third, Tony calls for integrating the measurement of poverty made by international organisations with the national analyses produced within each country. One of his recommendations in the CGP report was that the World Bank should produce brief 'National Poverty Statistics Reports' for each country (World Bank, 2017, pp. 28-9). The World Bank accepted this advice and has started to publish on its website short country 'poverty briefs'. In this opening chapter, Tony describes the selection of the sixty countries used as case studies of measurement, measurement described in the sixty two-page national reports at the end of the book. These national reports reflect his proposal although his implementation differs from the World Bank's, for example including more information on sources. They represent a key feature of the book. The existing literature tends to take either the global or the national perspective without reconciling the two, sometimes with highly confusing results. As Tony writes in the explanatory note to Figure 7.2, 'Zimbabwe has a poverty rate of 72.3 per cent when poverty is measured using the national line and a rate of 21.4 per cent when poverty is measured using the $\$ 1.90$ per person per day line. (These estimates refer to 2011.)' (MPAW, p. 179). On the other hand, he notes elsewhere that, "we may be more concerned with the trend than with the level and conclude that the estimates are congruent even if differently located' (MPAW, p. 163). His discussion of recent changes in poverty in rural China provides an example of where such congruency seems absent. The fall in the World Bank's estimate of the number of poor people between 2012 and 2013 using the \$1.90 line was 62.9 million, 'which was over half of the global fall between 2012 and 2013 of 114 million. In contrast, the 
figures supplied by the NBS [National Bureau of Statistics] show a fall of 16.5 million' (MPAW, p. 171).

In the national reports, Tony documents the measurement done at the national level by national statistical offices and ministries and the trends shown by these national data, comparing them with what is shown by data published by international organisations, notably the World Bank. Of course, for many countries there exist exercises comparing poverty estimates elaborated at the international and at the national levels, but the novelty of Tony's approach is to demand their systematic integration (but not full alignment). In his view, this serves to cross-check the conclusions on the structure and changes in poverty shown by different methods or sources, where inconsistencies that cannot be explained must sound a warning bell for users of the data. National measures are grounded in some kind of political process within each country, whereas the measures worked out by international organisations have a different origin. The integration of these two measurement exercises provides legitimacy to both, and eventually to the policy decisions that are taken based on them.

The importance of integrating these two measurement approaches could be seen also from the perspective of the tension between 'cosmopolitanism' and 'nationalism'. As we discuss in an Editors' footnote (MPAW, p. 209), Greenstein, Gentilini and Sumner propose to estimate global poverty as simply the sum of national head counts based on national poverty lines, because of 'the importance of national ownership and the incorporation of contextspecific measures of poverty, and that any new poverty goals should be designed with political mobilization as a consideration' (2014, p. 132; see also Gentilini and Sumner, 2012). This proposal reflects a 'nationalist' approach to the global poverty count, which refrains from establishing a common framework for measurement as implicit in the International Poverty Line. Rather than going this way, Tony suggests recognising the legitimacy of both approaches.

\section{The 'principled' approach}

The book is an example of the 'principled' approach followed by Tony throughout his research: there is no measurement without theory and conversely the theoretical developments are valuable only to the extent that they are liable to being used in practice. More importantly, ethical judgments are embedded in the measurement and researchers have the duty to make them explicit - the enduring insight of his 1970 JET paper. 
This approach is evident in the previous discussion but finds a neat illustration in Chapter 2. This chapter reviews a range of different concepts of poverty: 'political' definitions (standards adopted by governments to classify a person as poor or not), subjective assessments, basic needs, Nussbaum's and Sen's capability approach, and principles of human rights. It is a pity that Tony had no time to elaborate further on these issues as we think that he would have added more in time on the last of these concepts, perhaps commenting on the approach taken by the UN special rapporteur on extreme poverty and human rights in his country visits and annual reports. (Recent country visits include China, the UK, the USA, Ghana, Laos and Malaysia; the most recent annual report focuses on poverty and climate change (Alston, 2019).)

Each concept has implications for poverty measurement which become apparent in the following chapters. For instance, it is observed in Chapter 3 that focusing on multiple dimensions follows naturally from the capability and minimum rights approaches. At the end of Chapter 2 such implications are taken up in the context of the debate between absolute and relative measures of poverty. Thus, the basic needs approach may lead one to choose an absolute measure which has some scientific basis - although Tony warns that 'the idea of a purely physiological basis is illusory' (MPAW, p. 53) - whereas approaches focusing on individuals not in isolation but living in a society may favour a relative line. But Tony goes beyond this standard distinction to introduce the idea of what has come to be known as a 'societal' poverty line, following the work that he had done twenty years ago with François Bourguignon (Atkinson and Bourguignon, 2000 and 2001). The societal poverty line is an absolute one at lower levels of development but then moves up as national income rises, something rationalised using the capability approach. The 2018 edition of Poverty and Shared Prosperity, the World Bank's new biennial flagship report, published after Tony's book went to press, includes estimates of global poverty based on just such a 'societal' line following another of the recommendations of the CGP report. This is an important new research area (e.g. Ravallion and Chen, 2011, 2013, 2019; Chen and Ravallion, 2013; Ravallion, 2019b; Jolliffe and Prydz, 2019).

\section{A guide to statistical assumptions and data}

In Chapters 3 and 4 Tony provides a 'Checklist' of the questions he believed one should ask when faced with any statistics on poverty. Frequent references to illustrate the arguments are 
made to the sixty case studies of measurement provided by the national reports at the end of the book.

Chapter 3 focuses on clarifying the concepts. If a monetary measure is being used, what is being measured, consumption or income and how are these being defined? And for what period? How are differences in the cost of living across countries dealt with by the use of purchasing power parity exchange rates? How are differences in needs between households catered for and what about inequalities within the household (another new feature of data in Poverty and Shared Prosperity 2018 following the CGP report)? What about the depth of poverty, its severity?

Tony then moves on to non-monetary indicators, for example the absence of a particular item in the home or lack of access to clean water. He clearly wanted to give prominence to these measures of poverty, noting that the targets under the SDGs refer to reducing poverty 'in all its dimensions' (UN Sustainable Development Goals website). In part he could draw here on his long experience of research on social indicators in the EU (e.g. Atkinson et al, 2002), extended more recently to the global level (Atkinson and Marlier, 2010). What indicators are chosen in practice to measure an underlying dimension of e.g. health or education? How are indicators updated over time? Many of the available estimates of non-monetary poverty discussed in the book come from the work of the Oxford Poverty and Human Development Initiative (OPHI), building on the research there of Sabina Alkire, James Foster and their colleagues (e.g. Alkire and Foster, 2011, Alkire et al, 2015). For several years the OPHI estimates have been published in the UNDP's annual Human Development Report. Tony also covers Eurostat's measurement of material deprivation for the European Union. In both cases, classification of a household as poor is based on counting the number of indicators on which the household is classed as deprived.

Tony had a long-standing interest in the multidimensional measurement of poverty and inequality (e.g. Atkinson and Bourguignon, 1982) and pioneered the formalisation of the 'counting approach' as compared to the 'social welfare' approach (Atkinson, 2003). Were Tony to have completed his book, we think he would have continued to look for a 'middle ground' - as suggested by Ferreira and Lugo (2013) - in the debate that has surrounded these measures, pointing to the arguments on both sides while recognising that the measures have been adopted by many national statistical offices. He would have accounted for recent initiatives in rich countries that aim to broaden the measurement of poverty such as the Social Metrics Commission (2018) in the UK (an approach that the UK government has recently decided to implement in 2020 on an experimental basis) and Glassman (2019) in the USA. He 
would have discussed the World Bank's approach to estimating multidimensional poverty started with Poverty and Shared Prosperity 2018. The World Bank's approach differs from that taken by Tony in his book and recommended by him in the CGP report since a monetary measure of poverty is included as one of the indicators to be counted rather than the nonmonetary measures being kept separate as a complementary set of indicators. The Bank includes the monetary measure with a weight of $1 / 3$ in the main calculations with the result that 'anyone who is income poor is also poor under the broader poverty concept' (World Bank, 2018, p. 98). In the OPHI calculations that Tony draws on, estimates of multidimensional poverty are based on non-monetary indicators alone.

Chapter 4 considers the data underlying the statistics on poverty. What are they - do real data as opposed to imputations actually exist? Here, for example, Tony emphasises the importance of development aid from rich countries in improving the available sources in poorer countries. ('If you ask, "Where does our aid money go?", then one answer is the improvement of the information basis for monitoring and designing development policy' $(M P A W$, p. 105).) How comparable are the data between countries and over time? How well measured are price changes within countries, vital to the updating of national thresholds for monetary poverty? Who is missing from the sources used to measure poverty? What sorts of levels of response to sample surveys are achieved in practice? Can estimates be triangulated with information from other sources?

Chapters 3 and 4 extend over almost a hundred pages and cover virtually all problems arising in the empirical analysis of poverty. All different elements in the 'Checklist' should be considered together: what is needed is what Tony labels an 'All-round (AA) Approach'. Such an approach 'serves both to clarify the way in which a particular estimate has been reached which boxes have been ticked - but also alerts us to the fact that there are alternative choices that could lead to different conclusions about the extent and direction of change in measured poverty' (MPAW, p. 213).

Built on the unrivalled knowledge Tony accumulated in his lifelong research, his 'Checklist' provides an invaluable guide to anyone trying to estimate, or simply understand, poverty measures in practice, whether at the global or national level. Tony stresses that 'these issues are not nuisances to be left to the specialists': since 'they affect results, their comparability over time and across countries, and the soundness of policy conclusions, ... analysts and users must pay close attention to them' (MPAW, p. 145). On the other hand, these two chapters offer to specialists and data producers a starting point for further research. One case in point is the treatment of durable goods. Tony mentions the important distinction 
between the consumption of the good's services and the expenditure required to purchase the good, but he provides no further analysis of methods to deal with the problem or of what is done in practice around the world. In a very useful survey paper, Amendola and Vecchi (2014) note that official poverty measurement in the US, Canada, Australia and the UK ignores durables and that the same is true in 41 out of 95 poverty assessments carried out by the World Bank between 1996 and 2014 (covering 61 countries) in which the definition of the welfare aggregate was clear.

\section{From empirical trends to substantive questions}

Chapter 5 marks a transition in the book from considering concepts, measures and data sources, the subjects of Chapters 1 to 4 , to analysis of the existing data. Tony planned this chapter to look at the figures for poverty around the world produced by international organisations, picking up where Chapter 1 left off with the monetary measures produced by the World Bank (first reviewing the history of the World Bank's measurement of global poverty). He then intended to consider how rapidly poverty is falling on this basis and to show who it is that is living in poverty. This part of the chapter is largely missing. Next he planned to turn to the non-monetary measures of poverty published by the UNDP based on the work of OPHI. Do they tell the same story? Again, the analysis here is incomplete. Drawing on Tony's notes and files, we included some limited discussion of the data to address this question along the lines he had already started and point to directions that we think he would have taken the analysis.

Tony intended in Chapters 6-9 to do two things. First, he wanted to use the data he had assembled in the sixty national reports at the end of the book to answer a standard set of 'key questions' about poverty levels and trends for each of four regions or groups of countries Asia and the Pacific, Africa, Latin America and the Caribbean, and high income countries. In each case, he planned to compare the evidence from the national studies with the global estimates of poverty from the international agencies. Again, much of the analysis that he had wanted to include is missing and the existing literature that he would also have drawn on is only referred to sparsely.

The same is true for most of the second thing planned for these four chapters. Tony was to consider a series of 'general issues' - two per chapter - about the causes and correlates of poverty or about its measurement. These include: the extent of the 'trickle down' to the poor from economic growth and the impact on poverty of changes in inequality; the 
relationship between poverty reduction and climate change (the poor suffer most from changes in climate); the legacy from the colonial period to poverty today in former colonies (this reflecting his interest in income inequality in Africa back to the colonial period, e.g. Atkinson 2014); the poverty suffered by indigenous peoples; and the persistence of poverty in rich countries. This would have been a bold attempt to use the historical trends and structural patterns of poverty drawn from his national reports to illuminate fundamental questions about poverty. The discussion was not to be restricted to just the countries that made up the region or group with which the chapter was principally concerned, for example Asia in Chapter 6. $\mathrm{He}$ intended extensive cross-referencing to countries in other parts of the world, seeing these chapters as 'building horizontal bridges between the measurement of poverty at a national level in different countries' (MPAW, p. 162).

As noted earlier, we decided that the first two of these 'general issues' really should be covered in the published book, leading to our invitation to François Bourguignon and Nick Stern to write their afterwords. One of the issues to be dealt with in Chapter 9 was the estimation of global totals of monetary poverty based on the 'societal' poverty line introduced in Chapter 2. Here Tony made substantial progress, providing estimates for 2013 based on two different lines - yielding figures of 1.2 billion people and 2.0 billion people living in poverty. However, he had not yet taken the analysis further, by for example comparing his estimates with those of other authors who had used an analogous approach, albeit with important differences in the implementation of the basic idea (e.g. Ravallion and Chen, 2013; Jolliffe and Prydz, 2019, first released as working paper in May 2017), or by looking at changes over time (societal poverty declines more slowly with growth than poverty assessed using a yardstick of $\$ 1.90$ a day because the poverty line increases).

Chapter 10 concludes. The section titles show that Tony planned to draw together the main messages from each chapter of the book. He finishes in a characteristic upbeat way, his innate optimism on display. As far as the measurement of poverty is concerned, he argues that this cannot be static:

'The world is changing, notably on account of the rise of countries that were classified as 'low-income' a generation ago, but also because all societies evolve and their ambitions with regard to tackling poverty change over time. To meet the changing world, the analysis of poverty has to become richer and more subtle.' (MPAW, p. 210)

This, he notes, requires researchers to broaden their view: 
'Economists, statisticians, sociologists, and political scientists, among others, have to open their minds to new ways of thinking.' (MPAW, p. 210)

Moreover, he emphasises:

'The measurement of poverty is not a purely technical subject. This book is not like a guide to plumbing, because the right answers depend on views that are politically influenced and, at heart, matters of moral judgement. They are influenced by culture and by history. My hope is that the book will widen the ways in which poverty is viewed, allowing for a greater diversity of approaches.' (MPAW, p. 212)

(Is the reference to 'plumbing' an allusion to Esther Duflo's work? We were alerted to this possibility by Iacono (2019). Duflo's Ely lecture to the American Economic Association in January 2017, 'The Economist as Plumber' (Duflo, 2017), came just after Tony’s death but Duflo also gave the annual IMF Richard Goode lecture with the same title in early November 2016, of which Tony may well have been aware.)

Tony concludes that despite the holes in the data and their variable quality, in broad terms the evidence is already sufficient, in the sense that policy makers cannot say that they do not have the necessary information to tackle poverty. One section is titled 'We know enough to act'. He argues that what is lacking is political will. Politicians have accepted the ambitious goals for tackling poverty that are embodied in the SDGs and we now need to hold them to account.

\section{Conclusions}

Tony Atkinson's new book grew from his work chairing the CGP but it goes well beyond the CGP report. It is much broader both in approach and in content, and ambitious in trying to address a wide non-specialist audience. It is a classic Atkinson volume and in our foreword to the book we place it within Tony's career and huge research output since his first work on poverty in the late 1960 s.

In the event, considerable parts of the work remain incomplete. Our purpose has been to carry out the necessary editorial work to allow readers to appreciate the many insights contained in the draft left by Tony without nurturing an illusion that the book was almost 
finished. In this short paper, we have tried to highlight Tony's original contributions and promising research areas.

This is a book worth reading. It guides the reader through the many conceptual and empirical nuances of poverty measurement; while the focus is on global poverty, the analysis applies to measurement at any level, local, national or super-national. Yet, readers must be aware that it is an unfinished book. The unfinished chapters offer a foundation on which other researchers can build, and a challenge to them to do so. 


\section{References}

Alkire, S and Foster, J, 2011, 'Counting and multidimensional poverty measurement', Journal of Public Economics, 95: 476-487.

Alkire, S, Foster, J, Seth, S, Santos, M E, Roche, J M and Ballon, P, 2015, Multidimensional poverty measurement and analysis, Oxford University Press, Oxford.

Alston, P, 2019, 'Climate change and poverty. Report of the Special Rapporteur on extreme poverty and human rights', 25 June, Advanced unedited version, Office of the United Nations High Commissioner for Human Rights, Geneva.

Amendola, N and Vecchi, G, 2014, 'Durable goods and poverty measurement', Policy Research Working Paper 7105, The World Bank, Washington D C.

Atkinson, A B, 1969, Poverty in Britain and the reform of social security, Cambridge University Press, Cambridge.

Atkinson, A B, 1970, 'On the measurement of inequality', Journal of Economic Theory 2: 244-263.

Atkinson, A B, 1998, Poverty in Europe, Blackwell Publishers, Oxford.

Atkinson, A B, 2003, 'Multidimensional deprivation: Contrasting social welfare and counting approaches', Journal of Economic Inequality, 1: 51-65.

Atkinson, A B, 2014, 'The colonial legacy: Income inequality in former British African colonies', WIDER Working Paper 2014/045, UN University World Institute for Development Economics Research, Helsinki.

Atkinson, A B, 2015, Inequality: What can be done?, Harvard University Press, Cambridge, Mass.

Atkinson, A B, 2019, Measuring poverty around the world, Princeton University Press, Princeton, NJ.

Atkinson, A B, and Bourguignon, F, 1982, 'The comparison of multi-dimensioned distributions of economic status', Review of Economic Studies, 49: 183-201.

Atkinson, A B and Bourguignon, F, 2000, 'Pauvreté et inclusion dans une perspective mondiale', Revue d'économie du développement 8: 13-32 (English version published as 'Inclusion from a world perspective' in Governance, equity, and global markets, La Documentation Française, 179-192).

Atkinson, A B and Bourguignon, F, 2001, 'Poverty and inclusion from a world perspective', in J Stiglitz and P-A Muet, eds., Governance, equity, and global markets, Oxford University Press, Oxford, 151-166. 
Atkinson, A B, Cantillon, B, Marlier, E and Nolan, B, 2002, Social indicators: The EU and social inclusion, Oxford University Press, Oxford.

Atkinson, A B and Marlier, E, 2010, Analysing and measuring social inclusion in a global context, United Nations Department of Economic and Social Affairs, New York.

Brandolini, A and Carta, F, 2016, 'Some reflections on the social welfare bases of the measurement of global income inequality', Journal of Globalization and development 7 : $1-15$.

Chen, S and Ravallion, M, 2013, 'More relatively-poor people in a less absolutely-poor world', Review of Income and Wealth, 59: 1-28.

Duflo, E, 2017, 'Richard T. Ely Lecture: The economist as plumber', American Economic Review, 107: 1-26.

Faktorovich, A, 2019, 'An intricate economic analysis of a seemingly simple poverty calculation', Pennsylvania Literary Journal 11: 45-47.

Ferreira, F H G and Lugo, M A, 2013, 'Multidimensional poverty analysis: Looking for a middle ground', World Bank Research Observer 28: 220-235.

Gentilini, U and Sumner, A, 2012, 'What do national poverty lines tell us about global poverty?', IDS Working Paper 392, Institute of Development Studies, Brighton.

Glassman, B, 2019, 'Multidimensional deprivation in the United States: 2017', American Community Survey Reports, ACS-40, U.S. Census Bureau, Washington, DC.

Greenstein, J, Gentilini, U and Sumner, A, 2014, 'National or international poverty lines or both? Setting goals for income poverty after 2015', Journal of Human Development and Capabilities 15: 132-146.

Iacono, R, 2019, 'Book review: Measuring poverty around the world by Anthony B. Atkinson', LSE Review of Books, August 19.

Jolliffe, D M and Prydz, E B, 2019, 'Societal poverty: a relative and relevant measure', World Bank Economic Review: forthcoming.

Milanovic, B and Roemer, J, 2016, 'Interaction of global and national income inequalities', Journal of Globalization and Development, 7: 109-115.

Ravallion, M, 2019, 'Book review of Measuring poverty around the world', Journal of Economic Inequality, published online 28 August.

Ravallion, M, 2019a, 'Global inequality when unequal countries create unequal people', European Economic Review 111: 85-97.

Ravallion, M, 2019b, 'On measuring global poverty', NBER Working Paper 26211, Annual Review of Economics, 12: forthcoming. 
Ravallion, M and Chen, S, 2011, 'Weakly relative poverty', Review of Economics and Statistics, 93: 1251-1261.

Ravallion, M and Chen, S, 2013, 'A proposal for truly global poverty measures', Global Policy, 4: 258-265.

Ravallion, M and Chen, S, 2019, 'Global poverty measurement when relative income matters', Journal of Public Economics, 177: 104046.

Reddy, S and Lahoti, R, 2016, '\$1.90 a day: What does it say? The new International Poverty Line', New Left Review 97: 106-127.

Reddy, S and Pogge, T, 2010, 'How not to count the poor', in S Anand, P Segal and J Stiglitz, eds., Debates on the Measurement of Global Poverty, Oxford University Press, Oxford, 42-85.

Rodrik, D, 2017, 'Is global equality the enemy of national equality?', John F. Kennedy School of Government, Harvard University, Cambridge, mimeo.

Sivaraman, M R, 2019, 'Measuring poverty around the world', International Journal of Environmental Studies, published online 9 September.

Social Metrics Commission, 2018, A new measure of poverty for the UK. The final report of the Social Metrics Commission, The Social Metrics Commission, London.

World Bank, 2017, Monitoring global poverty: Report of the Commission on Global Poverty. World Bank, Washington, DC.

World Bank, 2018, Poverty and shared prosperity 2018: Piecing together the poverty puzzle. World Bank, Washington, DC. 